\title{
RENDIMENTO NO DESDOBRO DE Pinus sp. UTILIZANDO MODELOS DE CORTE NUMA SERRARIA DE PEQUENO PORTE
}

\author{
Alberto António Manhiça ${ }^{1}$, Márcio Pereira da Rocha², Romano Timofeiczyk Júnior ${ }^{3}$ \\ ${ }^{1}$ Eng. Florestal, M.Sc., Centro de Investigação Florestal, IIAM, Maputo, Moçambique - albertomanhica@ yahoo.com.br \\ ${ }^{2}$ Eng. Florestal, Dr., Depto. de Engenharia e Tecnologia Florestal, UFPR, Curitiba-PR, Brasil - mprocha@ufpr.br \\ ${ }^{3}$ Eng. Florestal, Dr., Depto. de Economia Rural e Extensão, UFPR, Curitiba-PR, Brasil - romano@ufpr.br
}

Recebido para publicação: 01/11/2010 - Aceito para publicação: 29/02/2012

\begin{abstract}
Resumo
O objetivo do presente trabalho foi comparar o desdobro convencional e programado de toras de pínus em uma serraria de pequeno porte, tendo sido utilizados modelos de corte para diferentes classes diamétricas aplicadas em um programa de computador MaxiTora, visando a otimização no desdobro de toras. Para tal, foram selecionadas 80 toras de Pinus sp. com diâmetros que variaram de 24 a $33 \mathrm{~cm}$, formando quatro classes diamétricas com 20 toras por classe. Em cada classe diamétrica, as toras foram separadas em dois lotes com 10 unidades, sendo um lote submetido ao desdobro aleatório e o outro lote submetido ao desdobro programado. Para o sistema de desdobro aleatório, os rendimentos obtidos em todas as classes diamétricas variaram de $44,96 \%$ a $52,47 \%$, com a média geral correspondendo a $49,01 \%$. No sistema de desdobro programado, os rendimentos obtidos variaram de $49,93 \%$ a $55,25 \%$ em todas as classes diamétricas estudadas e a média geral correspondeu a $52,14 \%$. A classificação de toras e programação de cortes permitiram aumentar o rendimento da serraria em pelo menos três pontos percentuais. A programação de desdobro de toras resultou em aumento de rendimento em todas as classes diamétricas estudadas.
\end{abstract}

Palavras-chave: Desdobro de toras; rendimento; otimização.

\begin{abstract}
Yeld in lumber of Pinus sp. using cutting models in small sawmill. The objective of this research was to compare conventional and programmed cutting of logs pine at small sawmill. The models have been used for cutting different diametrical classes. The software MaxiTora was employed aiming to optimize logs cutting. For such, $80 \operatorname{logs}$ of Pinus $s p$ had been selected with diameters that varied from $24 \mathrm{~cm}$ to $33 \mathrm{~cm}$, gathering four diametrical classes with $20 \mathrm{logs}$ each. In each diametrical class, the logs had been separated in two lots of 10 units, then the first lot was submitted to random cutting and the second lot was submitted to programmed cutting. In relation to the random cutting system, the yield obtained in all the diametrical classes varied from $44.96 \%$ to $52.47 \%$, and the general average corresponded to $49.01 \%$. In relation to the programmed cutting system, the yield varied from $49.93 \%$ to $55.25 \%$ in all the diametrical classes studied, and the general average corresponded to $52.14 \%$. Grading of logs and cutting schedule allowed to increase the sawmill efficiency in at least three percentage points. A programming sawing of logs resulted in increased yield in all diameter classes studied.
\end{abstract}

Keywords: Cut of logs; yield; optimization.

\section{INTRODUÇÃO}

O pínus constitui uma das essências florestais mais utilizadas no Brasil na indústria de madeira processada mecanicamente. A região Sul do país concentra a maior parte dessas florestas, sendo os estados do Paraná e de Santa Catarina detentores da maior área plantada com o pínus (Associação Brasileira da Indústria de Madeira Processada Mecanicamente (ABIMCI), 2007).

De acordo com Rocha (2002), o rendimento é um dos parâmetros que pode servir de base para os gestores da serraria avaliarem o seu desempenho, por revelar com relativa transparência se as operações estão sendo executadas corretamente no empreendimento. 
Para Tsoumis (1991), o rendimento de madeira serrada é influenciado por vários outros fatores que envolvem a espécie (diâmetro da tora, comprimento, conicidade e defeitos), máquinas de desdobro (linha de serragem, condição e manutenção dos equipamentos, variação da serragem), modelos de corte (dimensões da madeira serrada) e habilidade e experiência dos operadores das máquinas. Parte desses fatores também é mencionada por Vianna Neto (1984), acrescentando o tipo de produto a ser produzido e o grau de aproveitamento de subprodutos, como costaneiras, cavacos, refilos, destopos etc.

Na região Sul do Brasil, é comum encontrar várias serrarias pequenas processando a madeira de pínus usando um equipamento lento e técnicas não adequadas. A operação de desdobro é dependente da experiência do operador da máquina principal, para visualização de todas as alternativas na tora, de acordo com as suas características (diâmetro e defeitos), para a tomada de decisão visando a retirada de peças de madeira para atender o objetivo da empresa. Essa atitude, na maioria das vezes, resulta em níveis relativamente baixos de rendimento em madeira serrada, acarretando um aproveitamento inadequado da matéria-prima. Portanto, torna-se necessário adotar estratégias que visem assegurar o maior aproveitamento possível da matéria-prima na obtenção dos produtos desejados. Nesse contexto, é possível dispor de uma metodologia de desdobro de toras que envolva a classificação delas e o estabelecimento de modelos de corte para diferentes classes diamétricas, envolvendo um programa de computador que resulte na otimização da produção.

O objetivo desta pesquisa foi avaliar o rendimento em madeira serrada envolvendo uma comparação entre o desdobro aleatório e o programado, tendo sido utilizados modelos de corte para diferentes classes diamétricas aplicadas em um programa de computador MaxiTora, com vistas à melhoria no aproveitamento de Pinus sp.

\section{MATERIAL E MÉTODOS}

\section{Local do experimento e descrição da serraria}

O trabalho foi realizado em uma serraria de uma empresa localizada no município de Campina Grande do Sul, no Estado do Paraná. A empresa é composta por uma serraria e uma unidade de beneficiamento de madeira, dedicando-se à manufatura de produtos de madeira com maior valor agregado, como caixilhos, rodapés, painéis EGP (Edge Glued Panel) e outros produtos para a construção civil.

A serraria é de pequeno porte, uma vez que a sua produção de madeira serrada é menor que $500 \mathrm{~m}^{3} / \mathrm{mês}$, de acordo Vital (2008). Para levar a cabo as operações de desdobro de toras, a serraria dispõe de uma serra fita simples acoplada ao carro porta-tora, que é acionado pelo operador a partir do painel de controle, uma serra fita horizontal de dois cabeçotes para resserragem e uma serra circular múltipla de um eixo com três discos, dos quais um é móvel. A serra circular múltipla foi usada para o refilamento. O layout que ilustra a disposição das máquinas é apresentado na figura 1. A serraria apresenta baixo nível de automação, sendo que a operação dos equipamentos é dependente em parte da mão de obra. Na ocasião, a serraria operava com cinco funcionários.

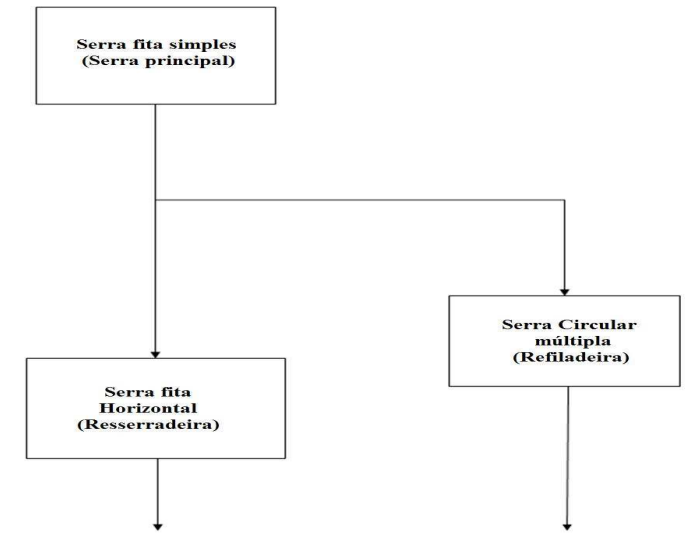

Figura 1. Layout da serraria ilustrando a disposição das máquinas.

Figure 1. Sawmill lay-out presenting the machines arrangement. 


\section{Espécie utilizada}

A espécie utilizada neste trabalho foi Pinus elliottii. A serraria recebia no seu pátio toras com diâmetros entre 24 e $33 \mathrm{~cm}$ e com comprimento que variava de 2,55 a 2,60 m. Ela tinha um consumo médio mensal de $1200 \mathrm{st}$ de toras, o equivalente a $827,59 \mathrm{~m}^{3}$, considerando o fator de empilhamento de 1,45 para toras de 24 a $33 \mathrm{~cm}$ de diâmetro.

\section{Seleção de toras e classes diamétricas utilizadas}

No pátio de toras, foram selecionadas 80 toras, que foram agrupadas em quatro classes diamétricas, com base no diâmetro médio ou se o diâmetro da ponta fina fosse igual ou superior ao limite inferior da classe considerada, tendo resultado em 20 toras por classe diamétrica (Tabela 1). As toras selecionadas receberam um número de identificação e foram pintadas na ponta fina para facilitar o controle no rastreamento desde o pátio até o final da linha de produção.

Tabela 1. Número de toras selecionadas por classe diamétrica.

Table 1. Number of logs selected by diametric class.

\begin{tabular}{lccc}
\hline $\mathbf{N}^{\mathbf{o}}$ & Classe diamétrica $(\mathbf{c m})$ & $\mathbf{N}^{\mathbf{o}}$ de toras selecionadas & Comprimento(m) \\
\hline 1 & $24,0---26,0$ & 20 & $2,55---2,60$ \\
2 & $26,1---28,0$ & 20 & $2,55---2,60$ \\
3 & $28,1---30,0$ & 20 & $2,55---2,60$ \\
4 & $30,1---33,0$ & 20 & $2,55---2,60$ \\
\hline Total & & 80 & \\
\hline
\end{tabular}

\section{Obtenção do volume de toras}

Para o cálculo do volume de toras, foram tomadas as medidas da circunferência na ponta fina e ponta grossa de cada tora selecionada. Pela divisão da medida de circunferência pelo $\pi$, foi obtido o diâmetro da ponta fina e o diâmetro da ponta grossa, e a média aritmética destes resultou no diâmetro médio. A partir desses dados foi calculado o volume de cada tora, usando-se a seguinte equação:

$$
V=\frac{3,14 * D^{2}}{40000} * L
$$

Em que: $\quad \mathrm{V}=$ volume da tora $\left(\mathrm{m}^{3}\right)$;

$$
\begin{aligned}
& \mathrm{D}=\text { diâmetro médio da tora }\left(\mathrm{cm}^{3}\right) ; \\
& \mathrm{L}=\text { comprimento da tora }(\mathrm{m}) .
\end{aligned}
$$

\section{Sistemas de desdobro usados}

As toras representantes de cada classe diamétrica foram separadas em dois lotes com 10 unidades. O primeiro lote foi submetido ao sistema aleatório de desdobro adotado pela empresa, e o segundo lote foi desdobrado de acordo com o modelo de corte preestabelecido com base no programa simulador MaxiTora para a classe diamétrica correspondente.

As toras foram desdobradas nos dois sistemas, para se obterem peças de madeira serrada nas seguintes dimensões: $42 \mathrm{~mm} \mathrm{X} 80 \mathrm{~mm}, 42 \mathrm{~mm} \mathrm{X} 120 \mathrm{~mm}, 42 \mathrm{~mm} \mathrm{X} 150 \mathrm{~mm}, 42 \mathrm{~mm} \mathrm{X} 180 \mathrm{~mm}$, $22 \mathrm{~mm} \mathrm{X} 80 \mathrm{~mm}$ e $22 \mathrm{~mm}$ X $160 \mathrm{~mm}$.

No sistema aleatório, as toras foram desdobradas de acordo com os critérios da empresa, sem que houvesse alguma intervenção nas operações. O sistema de desdobro predominantemente utilizado foi do tipo tangencial sucessivo, em que a tora era serrada em cortes paralelos uns aos outros, resultando em várias peças com faces planas, mas que requeriam o refilamento.

No sistema programado, foi usado o diâmetro médio da classe para gerar o modelo de corte correspondente. Cada tora foi desdobrada de acordo com o modelo de corte da classe diamétrica correspondente (Figura 2). As toras passavam pela serra principal definindo-se as espessuras finais, e em seguida passavam pela refiladeira, proporcionando às peças a largura final.

\section{Obtenção do volume de madeira serrada}

Em cada peça de madeira serrada obtida no desdobro foi medida a sua espessura e largura em três posições, utilizando-se um paquímetro digital, sendo duas medições a serem feitas a $20 \mathrm{~cm}$ das extremidades e a terceira medição na posição central da peça. 
O comprimento da peça não foi necessário medir, pois as toras já estavam destopadas para o comprimento final. Para efeitos de cálculo do volume de madeira serrada, foram utilizados os valores médios da espessura e da largura. As porções das peças que apresentaram esmoado foram medidas e excluídas no cálculo do volume da madeira serrada, a fim de se obterem volumes de madeira limpa. O volume individual da madeira serrada foi calculado com base na seguinte equação:

$$
V m s i=L g * E^{*} L
$$

Em que: $\quad \mathrm{Vms}_{\mathrm{i}}=$ volume da peça individual de madeira serrada $\left(\mathrm{m}^{3}\right)$;

$\mathrm{Lg}=$ largura da peça da madeira serrada $(\mathrm{m})$;

$\mathrm{E}=$ espessura da peça da madeira serrada $(\mathrm{m})$;

$\mathrm{L}=$ comprimento da peça da madeira serrada $(\mathrm{m})$.

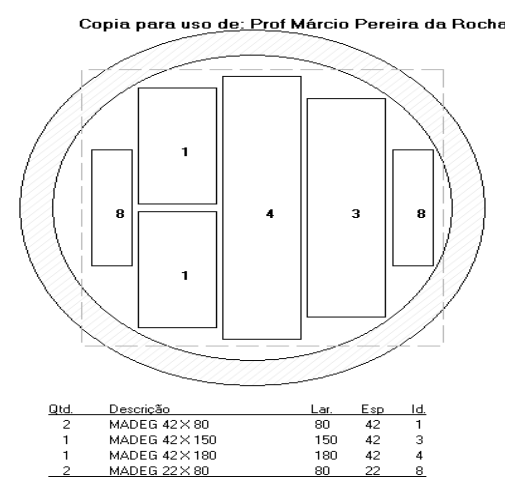

Diametro: 2500 Percentual de Aproveitamento: $49,10 \%$

Classe 1

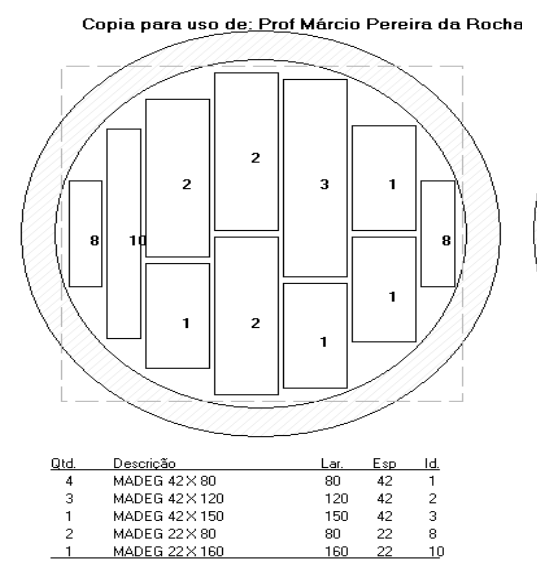

Diametro: 3160 Percentual de Aproveitamento: $53,43 \%$

Classe 3

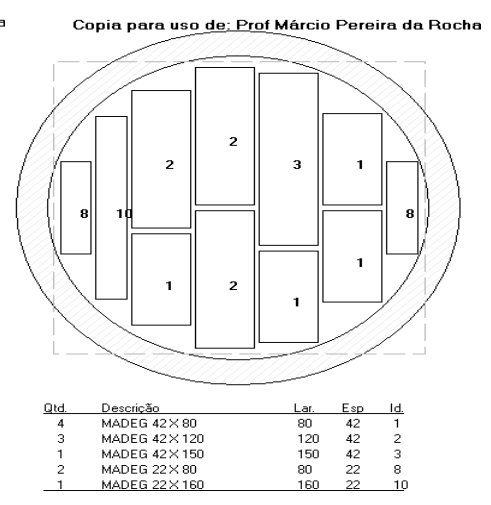

Diametro: 3160 Percentual de.Aproveitamento: $53.43 \%$

Classe 2

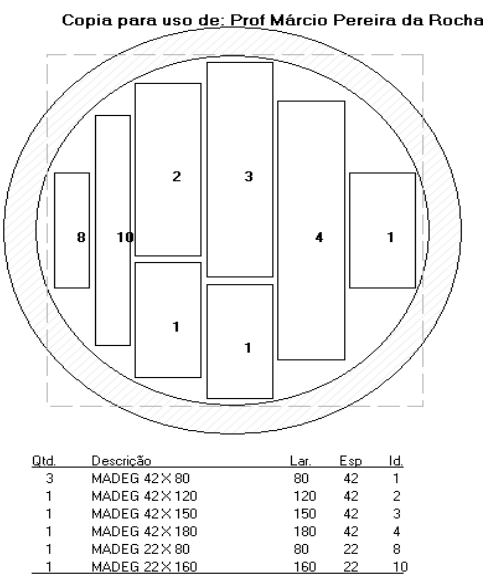

Diametro: 2910 Percentual de Aproveitamento: 51,51\%

Classe 4

Figura 2. Modelos de corte estabelecidos para quatro classes diamétricas.

Figure 2. Cutting models set for four diameter classes.

\section{Determinação do rendimento volumétrico da madeira serrada}

$O$ rendimento em madeira serrada dentro de cada classe diamétrica foi determinado com base na equação abaixo, citada por Rocha (2002): 


$$
R=\frac{V m s}{V t} * 100
$$

Em que: $\mathrm{R}=$ rendimento em \%;

$\mathrm{Vms}=$ volume total de madeira serrada $\mathrm{em}^{3}$ da tora;

$\mathrm{Vt}=$ volume da tora $\mathrm{em}^{3}$ utilizado para obter a madeira serrada.

\section{Análise estatística}

Neste experimento, foi avaliada a variável rendimento tanto para o desdobro aleatório como para o desdobro programado. Para tal, foi escolhido o delineamento inteiramente ao acaso, em que as classes diamétricas foram designadas por tratamentos. Cada tratamento tinha dez repetições. Foi feita a análise de variância para verificar se os tratamentos causaram um efeito diferente na variável rendimento em análise a $95 \%$ de probabilidade. O teste de comparação de médias (teste de Tukey) foi feito para discriminar as diferenças entre as médias dos tratamentos a $95 \%$ de probabilidade.

Para comparar as metodologias de desdobro (aleatório e programado) em função da variável em análise, foi escolhido o delineamento inteiramente ao acaso, obedecendo a um esquema fatorial com dois fatores, com o fator A sendo designado por metodologia de desdobro com dois níveis (desdobro aleatório e desdobro programado) e o fator B atribuído à classificação de toras com quatro níveis (classes diamétricas 1, 2, 3 e 4).

Os resultados estatísticos foram obtidos a partir do programa de computador MSTAT-C, versão 2.10 .

\section{RESULTADOS E DISCUSSÃO}

O teste de Bartllet feito sobre os valores da variável em análise (rendimento), tanto para o desdobro aleatório como para o desdobro programado, demonstrou haver homogeneidade de variâncias dos tratamentos a $95 \%$ de probabilidade, permitindo prosseguir com as análises de variância. No entanto, a análise de variância feita para cada metodologia de desdobro indicou que os tratamentos (classes diamétricas) apresentaram diferenças de rendimento estatisticamente significativas a $95 \%$ de probabilidade.

No âmbito da comparação entre os sistemas de desdobro aleatório e programado, a análise de variância demonstrou que as metodologias de desdobro apresentaram diferenças de rendimento estatisticamente significativas a $95 \%$ de probabilidade.

\section{Desdobro aleatório}

Na tabela 2 são apresentados os resultados dos rendimentos médios por classe diamétrica e podese observar que os rendimentos variaram de $44,96 \%$ a $52,47 \%$, sendo a média geral correspondente a $49,01 \%$.

Tabela 2. Rendimento obtido para diferentes classes diamétricas no desdobro aleatório.

Table 2. Yield of different diametrical classes in random cutting.

\begin{tabular}{|c|c|c|}
\hline Classe & Rendimento (\%) & Coeficiente de variação (\%) \\
\hline 1 & $44,96 \mathrm{c}$ & 4,65 \\
\hline 2 & $48,33 \mathrm{cb}$ & 3,79 \\
\hline 3 & $50,28 \mathrm{ba}$ & 6,89 \\
\hline 4 & $52,47 \mathrm{a}$ & 8,54 \\
\hline Média geral & 49,01 & \\
\hline
\end{tabular}

O teste de Tukey demonstrou que não houve diferenças significativas a $95 \%$ de probabilidade entre médias de rendimento das classes 1 e 2 , classes 2 e 3 , bem como entre as classes 3 e 4 , o que indica haver semelhanças entre as médias das referidas classes do ponto de vista estatístico. Por outro lado, foram registradas diferenças estatísticas entre as classes 1 e 3 , classes 1 e 4, assim como entre classes 2 e 
4 (Tabela 2). Entretanto, apesar das igualdades de médias de rendimento do ponto de vista estatístico entre duas classes consecutivas, pode-se observar a tendência de aumento de rendimento em função das classes diamétricas estudadas. Essas evidências demonstraram que o aumento do diâmetro de toras proporcionou o aumento significativo de rendimento, concordando com os estudos feitos por Ribas et al. (1989), Tsoumis (1991), Fontes (1994) e Egas (2002).

O rendimento médio geral da serraria encontrado a partir do desdobro aleatório correspondeu a $49,01 \%$, sendo considerado maior quando comparado ao rendimento médio obtido por Murara Júnior (2005) no desdobro convencional de pínus, que foi de 44,21\%, tendo trabalhado com diâmetros que variaram de 18 a $44 \mathrm{~cm}$ e com amplitude de classes diamétricas maior. De forma similar, o rendimento médio geral obtido na presente pesquisa também foi superior ao rendimento médio geral obtido por Valério et al. (2007) no desdobro da Araucaria angustifolia, que foi de 44,89\%, tendo trabalhado com diâmetros que variaram de $20 \mathrm{~cm}$ até mais de $60 \mathrm{~cm}$ e com amplitude das classes diamétricas maior. Ribas et al. (1989) estudaram o rendimento em madeira serrada e resíduos da serraria a partir do desdobro de toras de Pinus elliottii Engel. var. elliottii e obtiveram um rendimento médio de 46,95\%, tendo trabalhado com diâmetros que variaram de $12,1 \mathrm{~cm}$ a $27,0 \mathrm{~cm}$. Esse rendimento foi inferior ao rendimento obtido e apresentado na tabela 2.

Na presente pesquisa, trabalhou-se com a amplitude de diâmetro de toras menor $(24 \mathrm{~cm}$ a $33 \mathrm{~cm})$ e obteve-se um rendimento médio geral relativamente maior quando comparado aos rendimentos médios gerais obtidos pelos autores Ribas et al. (1989), Murara Júnior (2005) e Valério et al. (2007).

Ferreira et al. (2003) avaliaram a produção e a qualidade da madeira serrada de 10 clones híbridos de Eucalyptus. Na sequência, os autores classificaram as toras em função de defeitos e as desdobraram usando a serra fita simples, mediante o emprego de três métodos de desdobro tangencial, onde pelo método de desdobro tangencial balanceado paralelo ao centro da tora conseguiram obter um rendimento médio geral correspondente a 51,5\%. Esse rendimento foi superior em relação ao rendimento médio da serraria obtido, em que as toras foram desdobradas pelo método tangencial. As diferenças em diâmetros de toras desdobradas, a espécie usada, a qualidade de toras e o sistema de corte usado podem ter originado as diferenças de rendimentos obtidos nas duas pesquisas.

As classes 1 e 2 juntas perfazem um intervalo diamétrico de $24,0 \mathrm{~cm}$ a $28,0 \mathrm{~cm}$, de onde se obteve uma média de rendimento correspondente a 46,65\%. Esse rendimento médio foi superior em quase cinco pontos percentuais, comparando com o rendimento analisado por Murara Júnior (2005), que foi de $45,35 \%$. De forma similar, a classe $3(28,1$ a $30,0 \mathrm{~cm})$, com o rendimento de 50,28\% encontrando-se dentro do intervalo diamétrico de $28,1 \mathrm{~cm}$ a $34,0 \mathrm{~cm}$, com o rendimento de $45,31 \%$ analisado por Murara Junior (2005), foi superior em quase cinco pontos percentuais. Esses resultados podem constituir uma evidência de que a utilização de amplitudes de classes diamétricas menores pode contribuir para a obtenção de rendimentos relativamente maiores. Adicionalmente, o método de corte utilizado em cada um dos dois estudos também pode ter contribuído para as diferenças de rendimento registradas entre classes diamétricas.

No método aleatório, as toras foram desdobradas na serra principal segundo o corte tangencial. Tuset e Duran (1978) e Rocha (2002) mencionam que, com o corte tangencial, além da facilidade de aplicação, quando utilizado possibilita obter maior rendimento em madeira serrada, o que provavelmente pode ser a razão de se ter obtido nesta pesquisa um rendimento médio geral $(49,01 \%)$ superior ao rendimento médio obtido por outros autores. O modelo de corte tangencial possibilita a obtenção de peças de madeira com larguras maiores, o que é sustentado por Rocha e Tomaselli (2001). Esses autores, na sua pesquisa, avaliaram o efeito de dois modelos de corte (radial e tangencial), considerando toras de duas classes diamétricas nas dimensões de tábuas serradas de Eucalyptus sp., e concluíram que, de forma geral, o corte tangencial possibilita a obtenção de peças de maior dimensão e com maior valor comercial. Assim, a obtenção de peças com larguras maiores pode contribuir para maior rendimento em madeira serrada.

Em desdobro de toras na serra principal, eram retiradas basicamente peças de madeira com duas espessuras: $42 \mathrm{~mm}$ e $22 \mathrm{~mm}$. Enquanto as toras chegavam à serra principal para o desdobro, o operador avaliava cada uma em termos de suas características (diâmetro e defeitos), para o posicionamento da mesma em relação à serra fita, e decidia sobre a quantidade de peças a retirar para uma determinada espessura. 
A atitude de tomada de decisão por parte do operador da serra principal após a avaliação da tora refletiu-se de forma marcante no rendimento em madeira serrada obtido nas classes diamétricas estudadas e, portanto, da serraria. Os dados revelaram casos em que toras da mesma classe diamétrica apresentaram valores de rendimento muito variados. Esses fatos são fundamentados por Williston (1978), quando o autor referencia que o operador da serra principal tem maior responsabilidade no rendimento da serraria.

Por outro lado, o operador da refiladeira avaliava a largura de cada peça proveniente da serra principal e decidia sobre a largura final a retirar em várias opções de larguras que caracterizavam a linha de produto da empresa, dada a flexibilidade do equipamento no bitolamento. Em geral, o operador refilava peças na sua largura máxima. É importante ressaltar que o operador da serra refiladeira dependia completamente das peças provenientes da serra principal, mas também a sua tomada de decisão sobre a largura da peça a retirar influenciou o rendimento obtido a partir do desdobro de toras.

Nas classes 1 e 2 foram retiradas com maior frequência, na maioria das toras, peças de $42 \mathrm{~mm} \mathrm{x}$ $80 \mathrm{~mm}$. As peças de $22 \mathrm{~mm}$ x $80 \mathrm{~mm}$ e $22 \mathrm{~mm}$ x $160 \mathrm{~mm}$ não foram retiradas em todas as toras dessas classes.

Na classe 3 também foram retiradas com maior frequência peças de $42 \mathrm{~mm}$ x $80 \mathrm{~mm}$ em algumas toras. Em apenas uma tora é que foi retirada a peça de $22 \mathrm{~mm} \times 80 \mathrm{~mm}$.

Na classe 4 foram retiradas peças de madeira do mesmo tipo, como de $42 \mathrm{~mm}$ x $80 \mathrm{~mm}, 42 \mathrm{~mm}$ x $120 \mathrm{~mm}$ e $42 \mathrm{~mm}$ x $180 \mathrm{~mm}$, resultando em maior variabilidade de rendimentos obtidos em toras dentro da classe.

Assim, as peças de madeira serrada que caracterizavam a linha de produtos da serraria foram retiradas de forma completamente aleatória no desdobro de toras em todas as classes diamétricas, como resultado da atitude na tomada de decisão dos operadores da serra principal e da refiladeira influenciando o rendimento nessas classes.

\section{Desdobro programado}

A tabela 3 apresenta os valores médios do volume da tora, volume serrado e rendimentos por classe diamétrica, podendo-se observar que os rendimentos variaram de $49,93 \%$ a 55,25\%, sendo a média geral correspondente a $52,14 \%$.

Tabela 3. Rendimento para diferentes classes diamétricas no desdobro programado.

Table 3. Yield for different diametrical classes in programmed cutting.

\begin{tabular}{|c|c|c|}
\hline Classe & Rendimento (\%) & Coeficiente de variação (\%) \\
\hline 1 & $49,93 \mathrm{~b}$ & 2,91 \\
\hline 2 & $51,85 \mathrm{~b}$ & 4,07 \\
\hline 3 & $51,54 \mathrm{~b}$ & 4,28 \\
\hline 4 & $55,25 \mathrm{a}$ & 4,96 \\
\hline Média geral & 52,14 & \\
\hline
\end{tabular}

Os resultados dos rendimentos evidenciam que não houve diferenças significativas a $95 \%$ de probabilidade entre classes 1,2 e 3 , porém o valor médio de rendimento da classe 4 revelou ser estatisticamente superior e diferente dos valores das demais classes.

De uma maneira geral, foi possível reproduzir a maioria dos modelos de corte propostos pelo programa MaxiTora, apesar de ter havido casos em que, para algumas toras nas classes diamétricas estudadas, não foi retirada a última peça do modelo correspondente. O posicionamento não correto da tora em relação à serra por parte do operador da serra principal para retirada da primeira costaneira, que também está associado à localização do primeiro corte na tora, influenciou para a não retirada da última peça do modelo, afetando o rendimento em madeira serrada.

Para Haygreen e Bowyer (1982), uma vez feito o primeiro corte na tora, a localização dos cortes subsequentes para a retirada de peças de madeira é mais facilitada. Sendo assim, os autores referem que o volume da madeira serrada é determinado pelo primeiro corte na tora. Egas (2000) e Vital (2008) relatam que a localização não adequada do primeiro corte na tora afeta significativamente o rendimento em madeira serrada. 
Em toras com conicidade, a primeira peça retirada após a costaneira sempre apresentava muita casca, resultando em pouco aproveitamento após o refilo, devido à presença de esmoado, reduzindo o rendimento. As peças obtidas de toras com conicidade, ao seguirem para a refiladeira, eram refiladas em larguras menores, gerando maior volume de refilos, fato que de alguma forma prejudicou o rendimento. Assim, toras com conicidade apresentaram rendimentos relativamente baixos, o que contribuiu para a queda de rendimento em uma classe diamétrica, assim como para a serraria em geral.

Cardoso Júnior (2008) trabalhou com diferentes modelos de corte gerados pelo MaxiTora no desdobro de toras. $\mathrm{O}$ autor observou a influência da conicidade sobre o rendimento em madeira serrada, bem como na reprodução dos modelos de corte no desdobro de toras.

O MaxiTora, tratando-se de um programa bidimensional, não considera a conicidade e, como consequência, os rendimentos estimados pelo programa encontram-se subestimados, principalmente em toras com conicidade, pois o programa determinou o modelo com base no diâmetro mínimo. Dessa forma, a tora, ao ser desdobrada, acaba apresentando um rendimento maior. Sendo assim, o programa não possibilita retirar peças curtas, uma vez que só trabalha com duas medidas, que são a espessura e a largura.

Nas classes diamétricas estudadas houve aproximação entre os valores dos rendimentos reais obtidos na serraria e os rendimentos estimados a partir dos modelos de corte gerados pelo MaxiTora, exceto na classe 4 , em que a diferença entre o rendimento estimado $(53,43 \%)$ e o rendimento real $(55,25 \%)$ resultou em quase dois pontos percentuais. Sendo assim, pode-se dizer que os modelos de corte propostos pelo programa MaxiTora foram adequados para o desdobro de toras nas condições da serraria no que concerne ao layout e equipamentos, bem como à linha de produtos da serraria.

No geral, os rendimentos reais obtidos na serraria foram superiores aos rendimentos estimados dos modelos propostos em todas as classes diamétricas. Tal fato provavelmente aconteceu em função de que os valores reais de espessura e largura medidos em peças individuais de madeira serrada resultantes das toras desdobradas eram, na maioria das vezes, ligeiramente maiores que os valores nominais de espessura e largura.

O rendimento médio geral da serraria obtido pelo desdobro programado correspondeu a 52,14\%, sendo menor quando comparado ao rendimento médio geral encontrado por Murara Júnior (2005), que foi de 53,60\%, também obtido pela programação do desdobro. É importante salientar que o autor trabalhou com uma amplitude diamétrica maior, que foi de $18,0 \mathrm{~cm}$ a $44,0 \mathrm{~cm}$. Apesar de se ter trabalhado com uma faixa diamétrica menor $(24 \mathrm{~cm}$ a $33 \mathrm{~cm}$ ) na presente pesquisa, pode-se constatar que o rendimento médio geral obtido e o rendimento médio geral obtido por Murara Júnior (2005) resultaram numa diferença de dois pontos percentuais.

Por outro lado, o rendimento médio geral da presente pesquisa $(52,14 \%)$ obtido pelo desdobro programado foi superior ao rendimento obtido por Biasi e Rocha (2003), que foi de 43,17\%. Esses autores, apesar de terem trabalhado com modelos de corte para diferentes intervalos de diâmetros no desdobro de toras, obtiveram um rendimento médio geral relativamente baixo. É importante ressaltar que os autores trabalharam também com toras de diâmetro menor (abaixo de $15 \mathrm{~cm}$ ), o que pode ter influenciado negativamente o rendimento médio da serraria, uma vez que o desdobro de toras de diâmetro menor resulta em rendimento baixo.

Biasi e Rocha (2003) desenvolveram um estudo cujo objetivo era avaliar o rendimento em madeira serrada de pínus e puderam selecionar quatro lotes de toras com diâmetros variando de $8 \mathrm{~cm}$ a $45 \mathrm{~cm}$. As toras foram desdobradas de acordo com três diagramas de corte e foram obtidos rendimentos que variaram de $40,58 \%$ a $46,61 \%$.

Murara Junior (2005) desenvolveu um estudo visando avaliar o efeito da classificação de toras e modelos de corte sobre o rendimento em madeira serrada de pínus para o desdobro convencional e programado. Os resultados mostraram uma variação no rendimento para o desdobro convencional de $37,03 \%$ a $46,62 \%$. Por outro lado, os resultados do mesmo estudo mostraram também para o desdobro programado uma variação no rendimento de $44,93 \%$ a $63,58 \%$.

Na classe diamétrica 1, o rendimento real obtido na serraria $(49,93 \%)$ está de acordo com o rendimento proposto no modelo de corte correspondente, significando que o modelo foi reproduzido com sucesso. Contudo, houve uma tora em que não foi retirada a última peça do modelo (22 $\mathrm{mm}$ x $80 \mathrm{~mm})$, devido ao erro de posicionamento da tora pelo operador em relação à serra fita no primeiro corte. 
Na classe 2, apenas em uma tora não foi retirada a última peça do modelo correspondente, que apresenta a dimensão de $22 \mathrm{~mm}$ x $80 \mathrm{~mm}$, mas mesmo assim a reprodução do modelo permitiu obter um rendimento médio da classe satisfatório.

No entanto, a classe 3 apresentou um rendimento real ligeiramente menor que o rendimento obtido na classe 2 , em função de não ter sido retirada a última peça do modelo (42 $\mathrm{mm}$ x $80 \mathrm{~mm}) \mathrm{em}$ quatro toras, devido ao erro do operador, o que contribuiu para a queda do rendimento médio da classe. Esse fato pode ser a razão para as classes 2 e 3 apresentarem rendimentos reais próximos (Tabela 3 ).

$\mathrm{Na}$ classe 4 não foi retirada a última peça do modelo correspondente a $22 \mathrm{~mm}$ x $80 \mathrm{~mm}$ em cinco toras, devido ao erro do operador. A maioria das toras dessa classe apresentava a tendência de maior conicidade, o que, associado ao erro de posicionamento da tora em relação à serra principal e consequentemente, à realização do primeiro corte inadequado, contribuiu para queda do rendimento dentro da classe diamétrica 4.

No geral, o rendimento real obtido a partir do desdobro programado poderia ter sido maior em todas as classes diamétricas, se os fatores erro do operador e conicidade acentuada em algumas toras não tivessem influenciado na reprodução dos modelos de corte.

A classe $2(26,1 \mathrm{~cm}$ a $28,0 \mathrm{~cm})$ apresentou um rendimento de $51,85 \%$ e foi superior ao rendimento obtido na classe $2(24,1 \mathrm{~cm}$ a $28,0 \mathrm{~cm})$ de $48,02 \%$ na pesquisa desenvolvida por Murara Júnior (2005). De forma similar aconteceu também para a classe $4(30,1 \mathrm{~cm}$ a $33,0 \mathrm{~cm})$, que apresentou o rendimento de $55,25 \%$, sendo superior ao rendimento obtido na classe $3(28,1 \mathrm{~cm}$ a $34,0 \mathrm{~cm})$ no trabalho do mesmo autor, que correspondeu a $53,24 \%$. As classes 2 e 4 apresentaram uma amplitude diamétrica menor em relação às classes 2 e 3 do estudo feito por Murara Júnior (2005).

Apesar de o rendimento médio geral da presente pesquisa ter sido menor em relação ao rendimento médio geral obtido por Murara Júnior (2005), as classes diamétricas de $26,1 \mathrm{~cm}$ a $30,0 \mathrm{~cm}$ e $30,1 \mathrm{~cm}$ a $33,0 \mathrm{~cm}$ apresentaram melhores rendimentos. Biasi e Rocha (2003) encontraram rendimentos de $45,32 \%$ na classe $3(20,0 \mathrm{~cm}$ a $32,0 \mathrm{~cm})$ e $46,61 \%$ na classe $4(33,0 \mathrm{~cm}$ a $45,0 \mathrm{~cm})$, que foram inferiores aos rendimentos obtidos na presente pesquisa nas classes 3 e 4 , respectivamente. Assim, trabalhar com amplitudes diamétricas menores na geração de modelos de corte pelo programa MaxiTora é um fato que contribui para bons resultados na serraria em termos de rendimentos, visto que o MaxiTora é um programa muito sensível a pequenas variações de diâmetro, gerando modelos distintos.

\section{Comparação entre o desdobro aleatório e o desdobro programado}

A análise de variância do rendimento em porcentagem revelou que a interação dos fatores metodologia de desdobro (desdobro aleatório e programado) e classificação de toras testada (classes diamétricas 1, 2, 3 e 4) não foi significativa, indicando que são independentes (Tabela 4).

Os fatores principais, metodologia de desdobro e classificação de toras, apresentaram diferenças estatisticamente significativas a $95 \%$ de probabilidade. Os resultados do teste de comparação de médias de rendimento em madeira serrada para cada método de desdobro de toras e classes diamétricas estudadas são apresentados na tabela 4.

Tabela 4. Comparação de médias de rendimento entre o desdobro aleatório e o programado. Table 4. Comparison of average yield between programmed and random cutting.

\begin{tabular}{lccc}
\hline \multirow{2}{*}{$\begin{array}{l}\text { Classe } \\
\text { diamétrica }\end{array}$} & \multicolumn{2}{c}{ Rendimento (\%) } & $\begin{array}{c}\text { Média de rendimento } \\
\text { da classe (\%) }\end{array}$ \\
\cline { 2 - 3 } & Desdobro aleatório & Desdobro programado & $47,45 \mathrm{c}$ \\
2 & 44,96 & 49,93 & $50,09 \mathrm{cb}$ \\
3 & 48,33 & 51,85 & $50,91 \mathrm{~b}$ \\
4 & 50,28 & 51,54 & $53,86 \mathrm{a}$ \\
\hline Média geral & 52,47 & 55,25 & \\
\hline
\end{tabular}

Médias seguidas pela mesma letra maiúscula na horizontal e minúscula na vertical não diferem estatisticamente entre si pelo teste de Tukey a $95 \%$ de probabilidade.

O teste de Tukey revelou que o desdobro programado apresentou um rendimento médio geral $(52,14 \%)$ estatisticamente superior em relação ao rendimento médio geral $(49,01 \%)$ obtido pelo desdobro aleatório. 
Os resultados demonstram que a classificação de toras por diâmetro e a programação do desdobro melhora o rendimento da serraria. Analisando os valores absolutos de rendimento na tabela 4, observa-se que houve um aumento de rendimento em todas as classes diamétricas quando aplicada a metodologia de desdobro programado.

Na classe diamétrica 1 obteve-se, pelo desdobro aleatório, um rendimento de 44,96\%, mas, pelo desdobro programado, foi obtido o rendimento de $49,93 \%$, o que resultou num aumento de quase cinco pontos percentuais. Na classe diamétrica 2, o rendimento com o desdobro programado subiu em pelo menos três pontos percentuais. Igualmente verificou-se ganho para a classe 4, em que o aumento com a programação de cortes foi em pelo menos dois pontos percentuais. A classe 3 registrou uma diferença muito pequena entre as duas metodologias de desdobro, menor do que um ponto percentual.

Murara Júnior (2005), avaliando a classificação de toras e uso de modelos de corte no desdobro das mesmas, também registrou um incremento nos rendimentos em todas as classes diamétricas estudadas, devido ao desdobro programado.

No geral, as classes diamétricas 1, 2 e 4 indicam a evidência de que a programação de desdobro de toras, que consiste em utilização de modelos de corte específicos às classes diamétricas, tendo em conta a linha de produtos da serraria, permite o aumento do rendimento e, portanto, da produção em madeira serrada.

No entanto, a diferença em quase cinco pontos percentuais resultantes entre o desdobro aleatório e o programado na classe 1 é uma indicação de que no desdobro aleatório as toras não foram utilizadas adequadamente, dando lugar ao subaproveitamento da matéria-prima. A serraria, desdobrando toras da classe diamétrica 1 no volume de $40 \mathrm{~m}^{3} /$ dia, poderia obter, até o final do turno, $1,99 \mathrm{~m}^{3}$ a mais de madeira serrada, equivalendo a $41,79 \mathrm{~m}^{3} / \mathrm{mês}$ com o sistema de desdobro programado.

\section{CONCLUSÕES}

- O rendimento médio geral obtido a partir do desdobro aleatório nas condições da serraria em estudo foi reduzido pela falta de treinamento dos operadores da serra principal e da serra refiladeira.

- A classificação de toras e programação de cortes permitiram aumentar o rendimento da serraria em pelo menos três pontos percentuais.

- A programação de desdobro de toras resultou em aumento de rendimento em todas as classes diamétricas estudadas.

- O posicionamento da tora e a conicidade prejudicaram a reprodução dos modelos de corte gerados pelo programa MaxiTora, reduzindo o rendimento em madeira serrada.

- O desenvolvimento de uma nova versão do programa MaxiTora no contexto tridimensional poderá incluir fatores como a conicidade.

\section{RECOMENDAÇÕES}

- Realização de outros estudos de eficiência da serraria envolvendo a programação de desdobro de toras.

- Para a adoção de um sistema de desdobro programado na empresa onde ocorreu a pesquisa, é necessário que a serraria adote um sistema de classificação de toras por diâmetro, bem como desenvolva um programa de treinamento contínuo dos operadores das máquinas.

\section{REFERÊNCIAS}

ASSOCIAÇÃO BRASILEIRA DA INDÚSTRIA DE MADEIRA PROCESSADA (ABIMCI). Estudo setorial 2007: indústria de madeira processada mecanicamente: ano base 2006. Curitiba, 2007. 40 p.

Estudo setorial 2008: indústria de madeira processada mecanicamente: ano base 2007. Curitiba, 2008. $45 \mathrm{p}$.

BIASI, C. P.; ROCHA, M. P. Rendimento em serraria em Pinus elliottii. [S. 1.: s.n.], 2003. 12 p. 
CARDOSO JR., A. A. Inovação tecnológica na obtenção de madeira serrada com pinus com uso de programa optimizador de desdobro. Tese (Doutorado em Engenharia Florestal) - Setor de Ciências Agrárias, Universidade Federal do Paraná, Curitiba, 2008.

DENIG, J. Small sawmill handbook: Doing it right and making Money. San Francisco. Miller Freeman inc. $1993.182 \mathrm{p}$.

EGAS, A. F. Noções sobre a produção de madeira serrada. Maputo: UEM. 2000. 98 p.

FERREIRA, S.; LIMA, J. T.; ROSADO, S. C. S.; TRUGILHO, P. F. Influência de métodos de desdobro tangencial no rendimento e na qualidade da madeira de clones de Eucalyptus spp. CERNE. Lavras. v. 10, n. 1 , p. $10-21,2004$.

FONTES, P. J. P. Autossuficiência energética em serraria de Pinus e aproveitamento dos resíduos. Dissertação (Mestrado em Engenharia Florestal) - Setor de Ciências Agrárias, Universidade Federal do Paraná, Curitiba, 1994.

HAYGREEN, J. G.; BOWER, J. L. Forest products and wood science: An introduction. Iowa State University Press. 1. ed. 1982. 495 p.

MURARA JR., M. I. Desdobro de toras de Pinus utilizando diagramas de corte para diferentes classes diamétricas. Dissertação (Mestrado em Engenharia Florestal) - Setor de Ciências Agrárias, Universidade Federal do Paraná, Curitiba, 2005.

RIBAS, C.; ASSIM, J. L.; YAMAZOE, G.; GURCEL GARRIDO, L. M. Estudo da influência do diâmetro e do comprimento de toras de Pinus elliottii na produção de madeira serrada e de resíduos de serraria. Revista Instituto de Floresta, São Paulo, v. 1, n. 1, p. 51 - 65, 1989.

ROCHA, M.; TOMASELLI, I. Efeito de modelo de corte nas dimensões de madeira serrada de Eucalyptus grandis e Eucalyptus dunnii. Floresta e Ambiente, Seropédica, v. 8, n. 1, p. 94 - 103, 2001.

ROCHA, M. P. da. Técnicas de planejamento em serrarias. Série Didática FUPEF, Curitiba, n. 02/01, 121 p., 2002.

TSOUMIS, G. Science and technology of wood: structure, properties, utilization. New York: Chapman e Hall. 1991. 494 p.

VALÉRIO, A. F.; WATZLAWICK, L. F.; Dos SANTOS, R. T.; BRANDELEIRO, C.; KHOELER, H. S. Quantificação de resíduos e rendimento no desdobro de Araucaria angustifolia (Bertol.) O. Kuntze. Floresta, Curitiba, v. 37, n. 3, p. 387 - 398, 2007.

VIANNA NETO, J. A. Considerações básicas sobre o desdobro de Pinus spp. Silvicultura, Curitiba, Ano IX, n. 34, p 15-19, 1984.

VITAL, B. R. Planejamento e operação de serrarias. Viçosa, MG: UFV, 2008. 211 p.

WILLISTON, M. Lumber manufacturing: the design and operation of sawmills and planer mills. San Francisco: M. Freeman, 1978. 
